\title{
Research on the Ethical Principles of Enterprise Human Resources and Performance Management
}

\author{
Xiaoguo Yin \\ Henan Institute Of Economics And Trade, \\ Zhengzhou, Henan, 450000 China
}

\begin{abstract}
In this paper, we conduct the research on ethical principles of enterprise human resources and performance management. After entering the 21st century, great changes have taken place in the human society, began to turn industrial economic era to knowledge economic era. Global economic integration and to raise the level of competition makes any organization has to make full use of all their resources to ensure its survival and development. As an important organizational resource of the human resources has been more and more attention. Western countries as the most developed country in the world, is also the birthplace of the human resources management related theory and application of the more successful, select an object to the west as the comparison of the Chinese, to promote the improvement of Chinese enterprise human resources management is of great significance. Therefore, we conduct research on the topics which holds special meaning.
\end{abstract}

Keywords- Ethical Principles, Human Resources, Performance Management, Enterprise.

\section{Introduction}

In the process of enterprise human resources management, enterprise culture influences the success or failure of the modern human resource management is a very important factor. Many enterprises are the enterprise culture construction as an important content of the enterprise management innovation, improve the enterprise culture construction, to achieve objectives and long-term development plays an important role. Human resource management is an indispensable part of enterprise management, the status and importance in enterprise management is growing.
Therefore, in the competition of the economic globalization, the enterprise culture of inner spirit into the consciousness of manifestation of the acceptance, improve employee performance and especially improve team performance, so as to create enterprise economic benefits which have become an important topic in the human resources management of enterprises [1-3].

As we can see from the strength of human resource management concept analysis, to improve the effect of the practice of human resource management, not only to optimize the content itself, human resource management measures to let employees understand the measures and identify effectively, so that the implementation of these measures can be effective. (1) In the process of the implementation of the human resource management practices, basic employees can occur easily misunderstand some regulations or measures. In order to ensure effective implementation of the various human resource management measures, the organization must ensure that human resource management information are clear, and easy to understand. (2) The concrete measures of human resource management are only likely to be observed that employees could play their value and basic function. The degree of human resource management measures are easy to be observed is called visibility. Visibility into high and the low will not only affect employee on the general degree of attention to human resources management information and will affect their understanding of the information and organization. (3) Justification of human resource management functions and powers to a great 
extent relies on the support of senior managers, involving senior managers about the importance of human resources, investment in people, and human resources management expert participation in the strategic planning process. High power legitimacy of human resource management is more likely to get employees generally agree that and make staff to form the common belief [4-5].

The development of modern western human resource management theory with the new climax, as a representative of the theory of human capital theory, humanistic management theory and the theory of the learning organization from the macro investment, human resource, human resources management thought and the angle of sustainable development of the human resource management to explore the development of the human resource management in the new period, also appeared a strategic human resource management, international human resource management and basic political trend of human resource management research. In this paper to enhance the traditional approaches, we conduct the research on the ethical principles of enterprise human resources and performance management. In the figure one, we show the demonstration of the ethical principles.

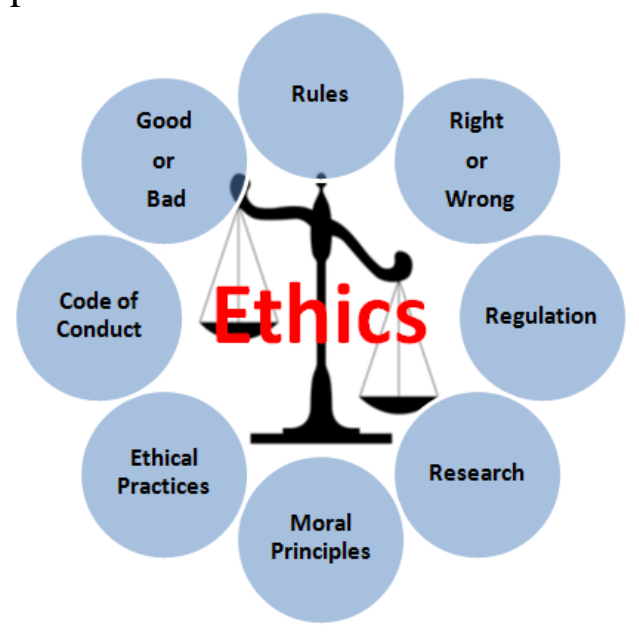

Figure 1. The Demonstration of the Ethical Principles

\section{The Proposed Methodology and Perspectives}

The Worker Performance Assessment. Performance management as one of the three cornerstones of modern human resources management, role in enterprise management, staff quality, performance directly affects the organization's overall efficiency and benefit, therefore, to master and improve the level of employee's work performance is an important responsibility of the enterprise operators and the managers. Purpose is not purely personal performance evaluation is designed, the deeper the purpose is to effectively promote the behavior of the individual, guide the enterprise staff begin to expand from the individual to the department or division, toward enterprise common strategic goal. Performance evaluation results directly affect the elevator, salary adjustment and job training, many aspects, such as education is closely related to the interests of the employees [6-7].

Accordingly, the functionality of the performance assessment could be summarized as the follows. (1) Enterprise staff positions, job change must have scientific basis, to ensure staff's enthusiasm that ensure the smooth progress in work and the completion of tasks of target and through comprehensive performance evaluation can accurately determine whether the employees' ability and quality in line with the requirements of their jobs, jobs, or can be aware of the change of an employee ability and the quality, in order to achieve some need to adjust their job or position. (2) Staff training is the human resources development and management of one of the most key link, as the trend of more and more shows that modern enterprises are gradually shift to the learning-type enterprise, staff training and quality enhancement will increasingly become the core of the enterprise sustainable development. And to understand the advantages and disadvantages of employees, it must be to get through to the individual performance evaluation. (3) For a while after the work, according to the complete situation give 
awards to inspire staff enthusiasm and the essential means to meet the needs of the employees. If you want to reasonable use, achieve fairness and justice, to the results of the performance evaluation as the basis. (4) In the process of performance evaluation, employees can see their own achievements, confidence, at the same time also can see their own shortcomings and the insufficiency, so that they can clear the direction of efforts, in order to do better in the future work.

With the advent of the era of knowledge economy, knowledge workers has gradually become the core object of human resource management, studies have shown that the turnover of knowledge workers is higher than general staff, the performance is not fully recognition and the respect are the important cause of departure, so do the knowledge staff's performance evaluation is a key link of its effective management. Practice, on the performance evaluation method of knowledge workers and many, however, managers often feel disoriented when trade-offs, one of the important reason is these evaluation methods usually does not emphasize application scenarios.

\section{The Business Management Pattern.} Enterprise management in the process of production by a certain command function, regulation function as business management can be divided into project management, procurement management, the quality management, production management, financial management, human resource management. Enterprises need to have clear goals in the process of development as constantly absorbing high-quality talent play to the staff's biggest potential enterprise can carry on the macroscopic regulation for resource, this way for enterprise investment and capital way of reasonable configuration. In the basic process of enterprise development, corporate image to constantly perfect, enterprise through their own role to provide more services for the society.

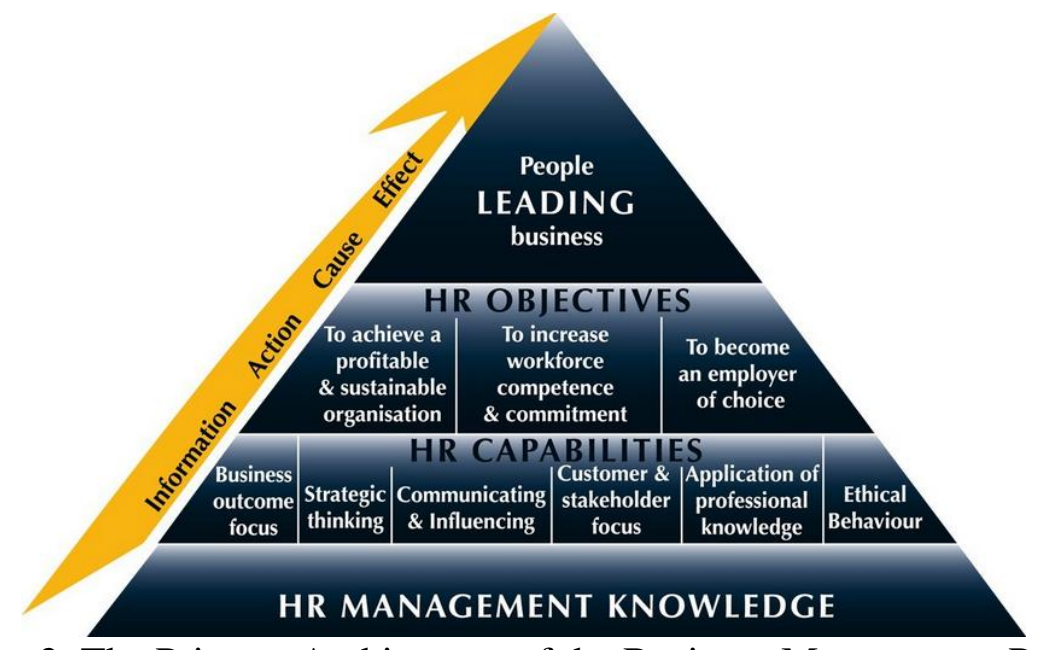

Figure 2. The Primary Architecture of the Business Management Pattern

Enterprises in the process of development, more and more domestic enterprises to the enterprise culture are also a new understanding, and this is the domestic enterprise facing a new challenge. In the challenge to complete their own breakthrough enterprise through a series of production experience, the construction process and development policy, the enterprise culture, enterprise culture is also for enterprise management concept and consciousness of the personnel the most real reflection. In the development process of enterprise to find a suitable for their own development policy of operating conditions, constantly improve its competition ability, enterprises in the basic process of continuous development for the past 
successful experience was summarized. Enterprise in the process of the management needs to have features of spiritual culture as the culture is also the embodiment of the enterprise centripetal force and cohesive force [8].

Introducing basic competition mechanism, implement target management responsibility system, improve the incentive mechanism, and can fully arouse the enthusiasm of archives management work and the management innovation, so as to promote the realization of the fine management. First of all, to make clear according to the need of management of archives management target, responsibility and accountability mechanisms, the work of long term and short term goals consistent, building their own goals and objectives; Secondly, establish the supervision and review of archives management effect mechanism, evaluation content depends on both job performance and also should see attitude and the ability to work, such ability helps to archives management personnel to develop good working habits to improve comprehensive quality and ability, which benefits implementation of fine management.

The Performance Theory. With development of the further research organization behavior and the human resource management in enterprise management plays a more and more important role, the study of performance has increasingly become a hot topic.

Technological innovation to promote economic growth is the deep law of market economy. Under the condition of market economy, when the capital deepening capital relative to labor and growth, the law of diminishing returns will play a role, with the increase of the capital accumulation, the marginal production decline, diminishing marginal returns. And technological innovation is a cyclical earnings decline curve up and moving outward, raised capital productivity changed the capital profit margins decline trend. In a market economy, diminishing returns with basic spontaneously contests between the technological innovation, technological innovation to a few steps away victory, it is technological innovation promotes the development of the economy, such is history progress. Under the condition of market economy, economic growth is a cycle. Schumpeter believes that in each cycle are important technological inventions and its commercial application caused a wave of technological innovation, the marginal profits to expand and promote economic prosperity [9].

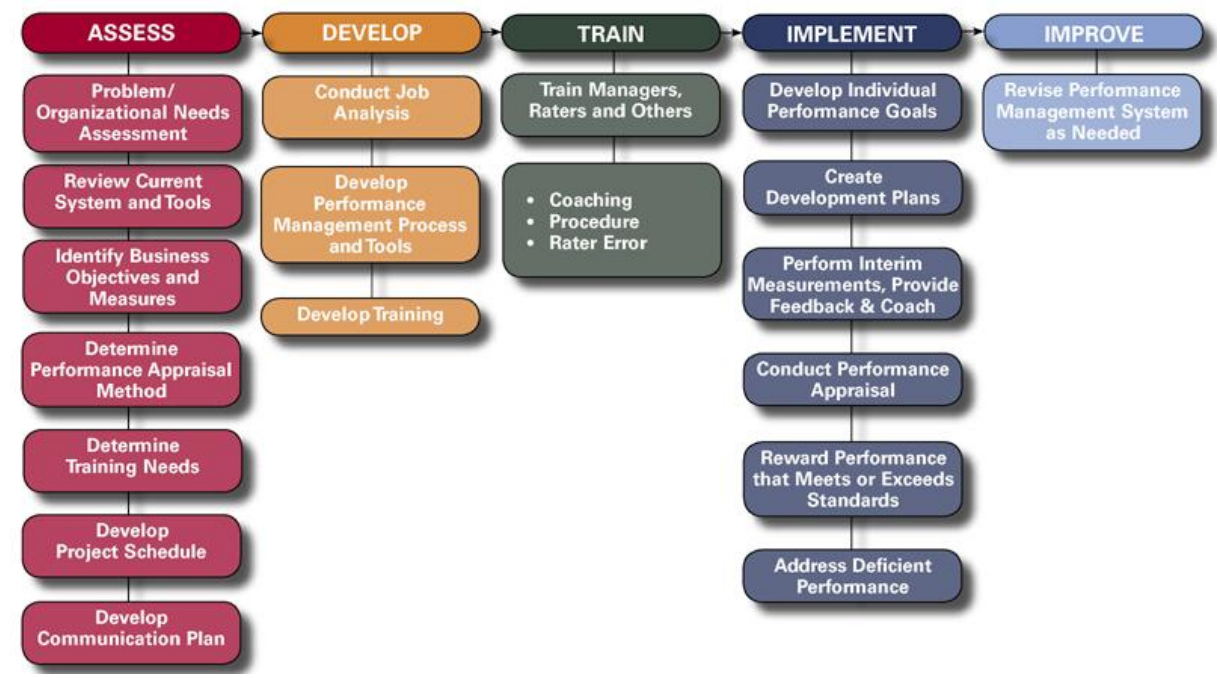

Figure 3. The Primary Components of the Performance Theory 


\section{The Future of the Enterprise Human} Resources and the Performance Management. Play an important role in the development of enterprise human resources, the rational utilization of human resources fully that has become an important task of enterprise management, scientific and correct strategy for the development of enterprise strategic human resources management role is becoming more and more attention. Modern enterprise human resources management should be centered on human resources, to achieve the rational allocation of basic corporate resources, the people as the constructive potential has intrinsic factors, and as decision enterprise survival and the development of special resources. To provide conditions for human resources, make its subjective initiative to give full play to their potential and their own labor. From content centered management to people-centered management, attaches great importance to the human resources development and the investment, to maximize human resource utilization degree, so as to realize the long-term goal of the enterprise core competitiveness and sustainable development [10].

To sum up, our country has a long history of human resource management and personnel thought, has the profound connotation. Along with the development of the western theory of human resource management, we should also keep pace with the times eclecticism, draw lessons from western human resource management of beneficial thoughts, rich human resources management theory and practice of our country. We in human resources management theory and practice, people should pay more attention to the body of the position and the important role, more fully give play to the role of the foundation of market allocation, inspired by restrictions on people to people to and change of human resources development, efforts to form talented people, develop people, use and dynamic mechanism of human resource management with Chinese characteristics. Along with the deepening of reform and opening-up, the global economic integration accelerating, the massive influx of foreign companies in China, the rapid development of private enterprises, completely changed the state-owned enterprises monopolize high quality human resources situation, made of talent drain in state-owned enterprises, comprehensive competitiveness greatly weakened. In this case, the state-owned enterprises to change the weak position in the war for talent, improve survival ability must change the traditional personnel system, the introduction of new management pattern of human resources and revitalize the existing human resources and strengthening talent development, raise the use efficiency of human resources and to attract talents which will holds positive function to the modern companies.

\section{Conclusion}

In this paper, we conduct the research on the ethical principles of enterprise human resources and performance management. In the field of the management, organization and management practice measures effects on final performance has always been the focus of theory and practice together. In recent years, due to the country to the "people-oriented" and the "harmonious management" business philosophy, stressed that the organization's human resources management is increasingly brought to the attention of the industry. Especially after the financial crisis, more and more companies keen to through effective human resource management measures to improve the staff's working enthusiasm, thus to enhance the competitiveness of the organization. Under this background and perspective, we conduct the theoretical analysis on the issues which is meaningful.

\section{References}

[1] Jiang, Shijun, and Chuanshu Zhu. "Study on the Supply and Demand Balance of Enterprise Human Resources Based on 
Statistical Prediction and Analysis." SHS Web of Conferences. Vol. 14. EDP Sciences, 2015.

[2] Nana, Zhou, and Du Du. "Building Harmonious Labor Relationship and the Management and Innovation of Enterprise Human Resources." Academic Exchange 2 (2013): 020.

[3] Margareta, Vîrcolici. "Improvement of Human Resources Management as the main factor for efficiency increase at an enterprise [J]." Development (2012).

[4] Li, Yao-hua. "Human Resources Cost Control Model of New Enterprise in Concept of Intelligent Logistics Backbone Network." 2014 2nd International Conference on Education Technology and Information System (ICETIS 2014). Atlantis Press, 2014.

[5] Sacala, Ioan Stefan, Mihnea Alexandru Moisescu, and Dragos Repta. "Towards the development of the future internet based enterprise in the context of cyber-physical systems." Control Systems and Computer Science (CSCS), 2013 19th International Conference on. IEEE, 2013.

[6] Xing, Jiangyong, and Kaiju Zhang. "Research and Practice of School Enterprise
Cooperation Training Orders after Sale Repair Engineers." 2014 International Conference on Global Economy, Commerce and Service Science (GECSS-14). Atlantis Press, 2014.

[7] Chang, Yu-Wei, and Ping-Yu Hsu. "Investigating switching intention to cloud enterprise information systems: an analysis at the organizational level." International Journal of Information Management (2016).

[8] Keig, Dawn L., Lance Eliot Brouthers, and Victor B. Marshall. "Formal and Informal Corruption Environments and Multinational Enterprise Social Irresponsibility." Journal of Management Studies 52.1 (2015): 89-116.

[9] Narimani, Mehdi, et al. "The impact of organizational citizenship behavior on enterprise resource planning success: The mediator role of TQM." International Journal of Quality \& Reliability Management 31.1 (2013): 53-65.

[10] Barchetti, Ugo, et al. "Collaborative process management for the networked enterprise: a case study." Advanced Information Networking and Applications Workshops (WAINA), 2012 26th International Conference on. IEEE, 2012. 